\title{
Are the habitat niches of female green pit vipers Cryptelytrops macrops and Viridovipera vogeli partitioned by vertical stratification?
}

\author{
CURT H. BARNES ${ }^{*}$, WILLIAM FARREN ${ }^{2}$, COLIN T. STRINE ${ }^{1}$, JACQUES HILL III ${ }^{3}$, \\ SURACHIT WAENGSOTHORN ${ }^{2}$, \& PONGTHEP SUWANWAREE ${ }^{1}$ \\ ${ }^{1}$ School of Biology, Institute of Science, Suranaree University of Technology, Nakhon Ratchasima, Thailand \\ ${ }^{2}$ Sakaerat Environmental Research Station, Nakhon Ratchasima, Thailand \\ ${ }^{3}$ Northwest Arkansas Community College, Bentonville, AR, USA \\ *Corresponding author e-mail: chradbarnes@gmail.com
}

\begin{abstract}
We used telemetry to track the movements of the females of two sympatric green pit viper species, Cryptelytrops macrops and Viridovipera vogeli, in north-eastern Thailand. This has generated information on their home ranges, lengths of displacements, and vertical niche partitioning. Five female vipers were tracked simultaneously within the same general habitat for 78 days in the cold, dry season for a mean of $113.6 \pm 5.38$ (range: $101-129$ ) fixes. The data show that $V$. vogeli had larger home ranges and greater displacements than C. macrops ( $0.49 \pm 0.02$ and $0.26 \pm 0.07$ ha, $38.01 \pm 9.72$ and $25.12 \pm 2.40 \mathrm{~m}$; respectively). Interestingly, $V$. vogeli selected arboreal sites significantly more frequently (mean $53.0 \pm 14.4 \%$ of observations, range 38.6- 67.5) than sympatric C. macrops (mean $23.4 \pm 13.2 \%$, range $5.3-49.2$ ). We cautiously suggest that vertical stratification of these two sympatric vipers may be one factor facilitating the co-existence of otherwise morphologically similar species.
\end{abstract}

\section{INTRODUCTION}

f two or more species in an ecosystem occupy a similar niche then they will usually compete for resources (Gause, 1934) and if environmental factors remain constant, one species will eventually outcompete and exclude the other (Hardin, 1960). Interspecific competition for resources ultimately imposes higher energy costs on all competitors (Abramsky et al., 2001). Interspecific competition can be avoided by niche partitioning, when sympatric species develop different resource preferences (Wisheu, 1998), or when a population becomes regulated more by conspecifics than interspecifics (Chesson, 2000). In a landmark study on interspecific competition, Pacala \& Roughgarden (1982) observed that Anolis species that partitioned feeding sites faced less conflict and competition than sympatric species that did not.

In snakes, food partitioning often takes greater priority over space between individuals, compared to other vertebrates (Toft, 1985), likely due to selection pressure for divergence in food types (Roughgarden, 1976). Intraspecific niche partitioning has been suggested for several snake species (Shine \& Wall, 2007). Of the estimated 46 green pit viper species found in Asia (Vogel et al., 2014) many show sexual dimorphism of mass and snout-to-vent length. This includes the species of the current study, Cryptelytrops macrops Kramer 1977 and Viridovipera vogeli David et al. 2001 (Malhotra et al., 2004; Strine et al., 2015) and their dimorphism suggests some degree of intraspecific prey partitioning as males display different spatial ecology from females (Stuart et al., 2012; Barnes et al., 2017).
Viridovipera vogeli and C. macrops are both viviparous, typically arboreal and inhabit Thailand's Sakaerat Biosphere Reserve (Kramer, 1977; David et al., 2001; Strine et al., 2015). These two sympatric species normally forage near water for frogs and other potential prey (Orlov et al., 2002), and thus occupy similar niches (as defined by Gause, 1934). Here we present a telemetry study of females of the two viper species giving preliminary evidence of home range sizes, movement patterns and vertical niche partitioning. Males were not included as their small size makes them unsuitable subjects for telemetry (Strine et al., 2015; Barnes et al., 2017).

\section{MATERIALS AND METHODS}

The study was undertaken in the dry evergreen forest of the Sakaerat Biosphere Reserve (for details of the Reserve see Trisurat et al., 2009). The two green pit viper species of the study were captured during opportunistic searches at night. Morphometrics (mass, SVL, etc.) were determined the following day with the acrylic tube method and isoflurane anaesthesia as described by Wilkinson (2014). We surgically implanted Holohil BD-2 and BD-2T $1.8 \mathrm{~g}$ transmitters into the body cavities of vipers following Reinert \& Cundall (1982) and Hardy \& Greene (2000). Transmitter mass was less than $5 \%$ of the viper body mass. Vipers were returned to their location of capture within 72 hours.

Vipers were sought daily, once during day light and once at night time, and during every fix we attempted to obtain visual confirmation. Daytime is typically the inactive period (when they were most likely to be sheltering or resting) 
and night the active period (most frequently ambushing, moving, etc.). We minimised disturbance to individuals by approaching slowly, identifying the location of the snake, and then immediately retreating from the subject to approximately $5 \mathrm{~m}$ for data collection. We defined vertical strata as underground, on ground, groundstorey $(<1 \mathrm{~m}$ above the ground), understorey (1-3 m), midstorey (3$10 \mathrm{~m})$, and abovestorey (>10 m). The category "arboreal" referred to observations in the midstorey or abovestorey categories. Utilising categorical data allowed for simple data collection, thus minimising disturbance to the viper in the field. Snake locations were determined with handheld GPS units (Garmin GPSMap64s) to the highest accuracy possible (usually 5-12 m), confirmed later using ArcGIS 10.1 (ESRI, 2012). Displacements of $>5 \mathrm{~m}$ were considered a "move" for consistency with the level of GPS accuracy. We calculated number of moves, mean distance per move, and mean daily displacement (MDD, number of days tracked divided by distance moved) and provide descriptive statistics.

We radiotracked three female $C$. macrops and two female V. vogeli between July 2014 and February 2015 for 92-215 days $($ mean $140.6 \pm 26.12$, median $=110$, Table 1$)$ but analyses were confined to data collected from 11 November, 2014 to 27 January, 2015 (78 days) when all vipers were tracked simultaneously. This was the cold, dry season in north-east Thailand. We calculated minimum convex polygon (MCP, 100 $\%$ ) and fixed kernel (50 and $99 \%$ ) home range size, using the adehabitatHR package (Calenge, 2006) in program R (version 3.1.2; R Development Core Team, 2010). Accuracy of fixed kernel and MCP methods have previously been questioned (Row \& Blouin- Demers, 2006), but are used for comparative purposes in this work. To select the smoothing factor for core $(50 \%)$ and activity $(99 \%)$ area utilisation distributions, we employed the least- squares cross validation method (Tiebout \& Cary, 1987).
Table 1. Summary of the radio-tracked C. macrops (CRMA) and $V$. vogeli (VIVO), including snout- vent length (SVL), total tracking duration of each viper, number of fixes during study period (11 November, 2014 to 27 January, 2015), and \% fixes observed arboreal (>3 $\mathrm{m}$ above ground level) during study period

\begin{tabular}{|ccc|cc|cc|}
\hline \multirow{2}{*}{ Viper ID } & \multirow{2}{*}{ SVL } & Mass & \multicolumn{2}{|c|}{ Tracking } & $\begin{array}{c}\text { Number } \\
\text { of fixes }\end{array}$ & $\begin{array}{c}\text { \% time } \\
\text { arboreal }\end{array}$ \\
\hline CRMA174 & 534 & 43.7 & 7th Oct & 27th Jan & 122 & 5.3 \\
CRMA178 & 594 & 44.5 & 11th Nov & 13th Feb & 129 & 15.7 \\
CRMA186 & 592 & 44.8 & 8th Nov & 12th Feb & 113 & 49.2 \\
VIVO002 & 729 & 200 & 7th Jul & 12th Feb & 101 & 67.5 \\
VIVO003 & 720 & 202 & 29th Jul & 13th Feb & 103 & 38.6 \\
\hline
\end{tabular}

We also used dynamic Brownian Bridge Movement Models (dBBMMs; Karelus et al., 2017; Kranstauber et al., 2012; Silva et al., 2018) for a more modern approach of quantifying utilisation distributions (UD) as home ranges and movement. Unlike MCP and kernel density estimates, which do not account for spatially autocorrelated animal movement data (Kranstauber et al., 2012), dBBMMs incorporate the temporal structure of animal locations to estimate UDs based on their movement's trajectory. We set the dBBMM moving window size to 9 (equivalent to 9 days) and margin size of 3 to detect possible changes in movement between 3-day periods for all vipers except for CRMA174 (window size $=21$, margin size $=$ 9), and telemetry location error to the average GPS accuracy obtained in the field $(8 \mathrm{~m})$. We used $90 \%$ and $95 \%$ dBBMM isopleth contour UDs to represent areas of 'core utilisation' and a more generous 'total utilisation,' as these larger contours predict a more accurate area of use without oversmoothing (Walter et al., 2011). Movement and home range dBBMMs were calculated in $\mathrm{R}$ using adehabitatHR (Calenge, 2006), BBMM (Nielson et al., 2011), and ctmm (Calabrese et
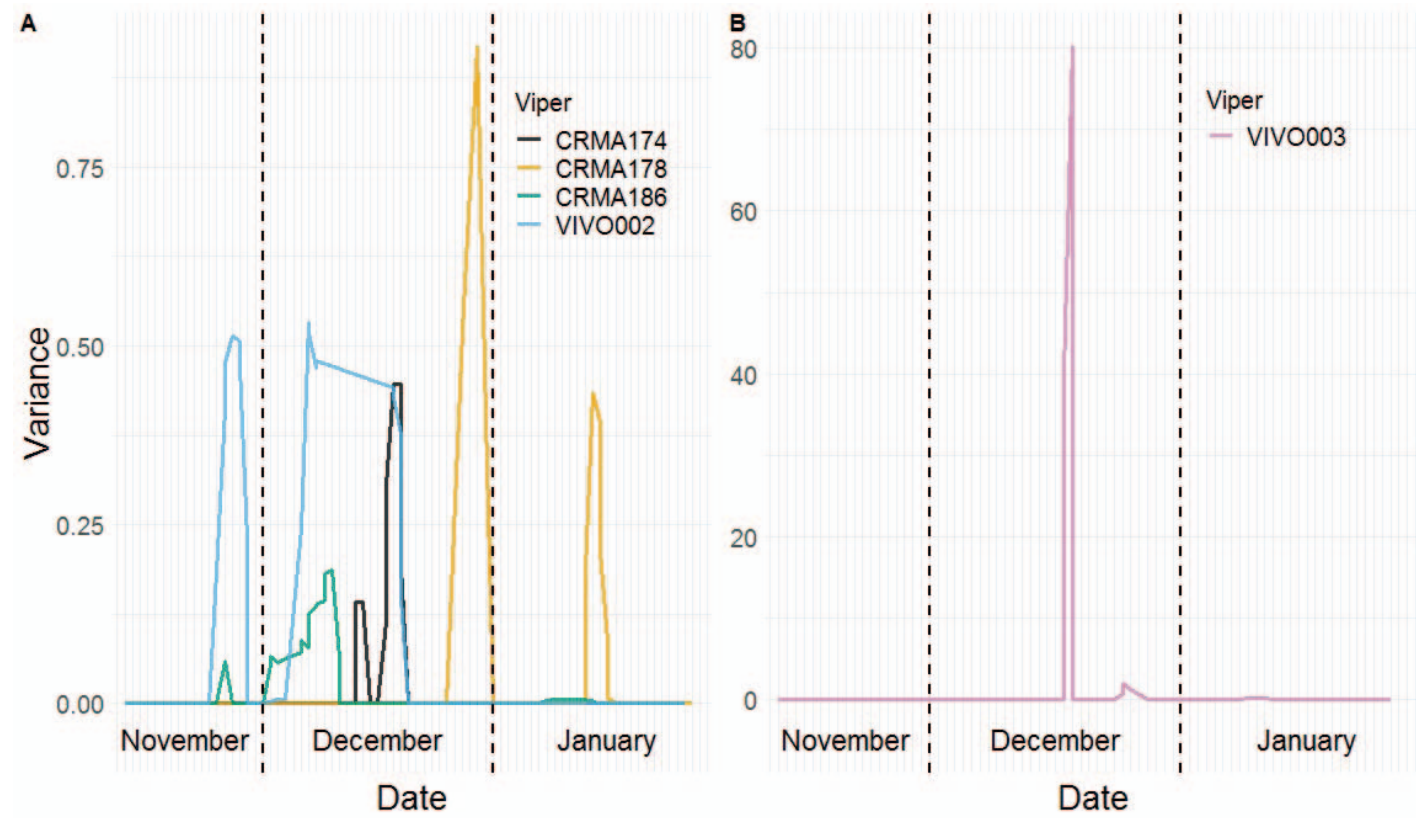

Figure 1. Movement variance estimation $\left(\sigma^{2} \mathrm{~m}\right)$ over time for four green pit vipers with similar movement (A), and one viper with very high movement during the middle of December (B) during intensive study period between 11 November, 2014 to 27 January, 2015, with dashed lines indicating start and end of calendar months 
Table 2. Movement and home range summary of radio-tracked C. macrops (CRMA) and $V$. vogeli (VIVO), including the number of displacements (moves), mean distance per displacement $(\mathrm{m})$, mean daily displacement (MDD, $\mathrm{m})$, and minimum convex polygon (MCP, 100\%, ha), kernel (50 \% FK and 99 \% FK, ha), and dynamic Brownian Bridge Movement Model (90 \% dBBMM and 95 \% dBBMM, ha) home ranges

\begin{tabular}{|c|c|c|c|c|c|c|c|c|}
\hline Viper ID & Moves & Mean distance & MDD & MCP & $50 \% \mathrm{FK}$ & $99 \% \mathrm{FK}$ & $\begin{array}{c}90 \% \\
\text { dBBMM }\end{array}$ & $\begin{array}{c}95 \% \\
\text { dBBMM }\end{array}$ \\
\hline CRMA174 & 10 & 28.1 & 0.23 & 0.41 & 0.15 & 1.01 & 0.42 & 0.64 \\
\hline CRMA178 & 14 & 26.9 & 0.21 & 0.18 & 0.15 & 0.91 & 0.49 & 0.81 \\
\hline CRMA186 & 17 & 20.4 & 0.18 & 0.20 & 0.07 & 0.48 & 0.36 & 0.52 \\
\hline Mean & 13.67 & 25.12 & 0.21 & 0.26 & 0.12 & 0.80 & 0.43 & 0.66 \\
\hline SE & 2.03 & 2.40 & 0.01 & 0.07 & 0.02 & 0.16 & 0.04 & 0.08 \\
\hline Median & 14 & 26.85 & 0.21 & 0.20 & 0.15 & 0.91 & 0.42 & 0.64 \\
\hline VIVO002 & 14 & 28.3 & 0.28 & 0.47 & 0.20 & 1.33 & 1.07 & 2.34 \\
\hline VIVO003 & 11 & 47.7 & 0.46 & 0.51 & 1.17 & 5.89 & 0.86 & 2.33 \\
\hline Mean & 12.5 & 38.01 & 0.37 & 0.49 & 0.68 & 3.61 & 0.97 & 2.34 \\
\hline SE & 1.5 & 9.72 & 0.09 & 0.02 & 0.49 & 2.28 & 0.04 & 0.01 \\
\hline Median & 12.5 & 38.01 & 0.37 & 0.49 & 0.68 & 3.61 & 0.97 & 2.34 \\
\hline
\end{tabular}
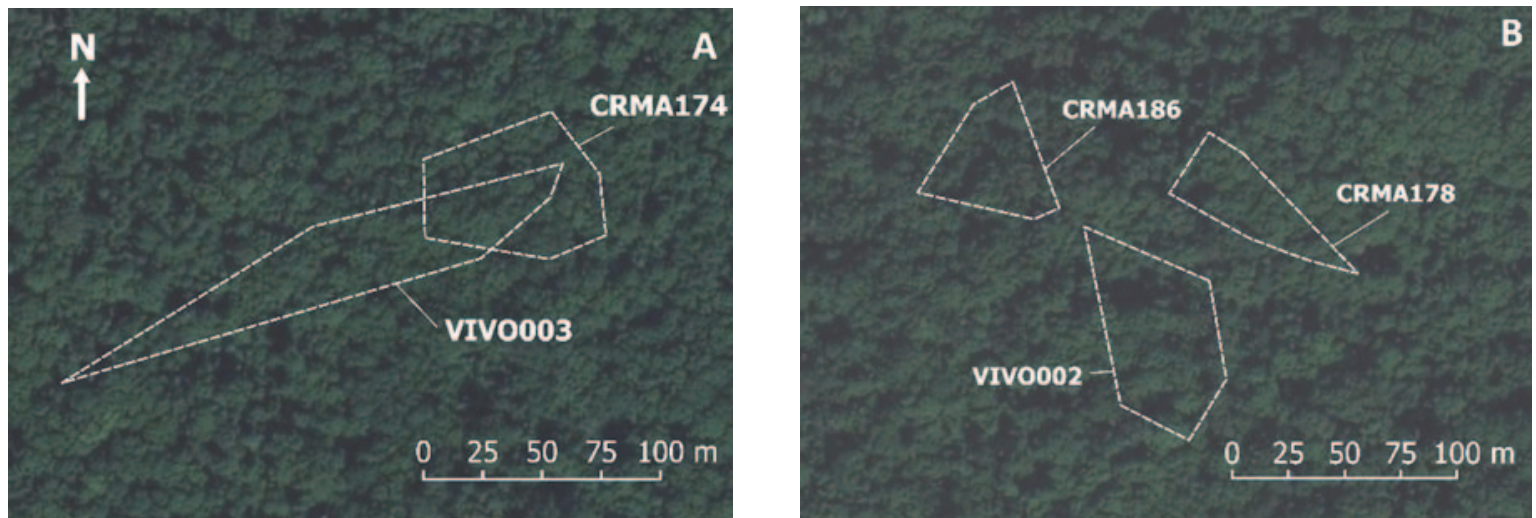

Figure 2. Maps of green pit viper minimum convex polygons (MCP, $100 \%$ ); A. CRMA174 and VIVO003, B. CRMA178, CRMA186, and VIVO002

al., 2016) packages.

Spatial overlap was calculated using UD overlap index (UDOI, Fieberg \& Kochanny, 2005) with the R package KernSmooth for fixed kernels and the intersect function in QGIS (version 2.12.3; Quantum GIS Development Team, 2016) for MCP overlap analysis. Overlap is presented as area (ha and \%) for MCP and as the UDOI for kernels. Values from the UDOI range from $<1$ which suggests less overlap relative to uniform space use, 1 if both home ranges are uniformly distributed and have $100 \%$ overlap, and values $>1$ indicate higher than normal overlap relative to uniform space use. We also present results from 2 relatively infrequently used indices for comparative purposes; volume of intersection index (VI, Seidel, 1992; Kernohan et al., 2001) and Bhattacharyya's affinity (BA, Bhattacharyya, 1943), both of which range from 0 (no overlap) to 1 (identical home ranges); advantages and biases of all overlap methods are discussed in Fieberg \& Kochanny (2005).

Due to small sample size, we compare overlap values and provide descriptive statistics for home ranges. Means are reported for data with standard error and medians. Due to our small sample size and categorical data, we used Chisquare tests with the chisq.test function in program $\mathrm{R}$ to assess differences in arboreality between the two study species.

\section{RESULTS}

In the 78 day period in which all vipers were tracked simultaneously, C. macrops were tracked more frequently ( mean $121.3 \pm 4.63$ fixes, median $=122$, range 113-129 fixes) than the $V$. vogeli (mean $102 \pm 1$ fixes, median $=102$, range 101-103 fixes). The two $V$. vogeli were longer and heavier than the three $C$. macrops (Table 1) and all were within the typical adult size range for their respective species.

The five vipers undertook an average of $13.2 \pm 1.24$ (median $=14$, range 10-17) displacements, moved 30.28 $\pm 5.00 \mathrm{~m}$ (median $=28.14 \mathrm{~m}$, range $20.38-47.74 \mathrm{~m}$ ) per displacement, and had mean daily displacements of 0.27 $\pm 0.05 \mathrm{~m}$ (median $=0.23$, range $0.18-0.46 \mathrm{~m} /$ day) (Table 2). Vipers moved most frequently during mid- December, however, peaks of movement activity were observed at the end of November and also middle of January (Fig. 1). Mean MCP home range size for all individuals was $0.35 \pm 0.07$ ha (median $=0.41$, range 0.18-0.51 ha); $50 \%$ and $99 \%$ kernels were $0.35 \pm 0.21$ ha (median $=0.15$, range $0.07-1.17 \mathrm{ha}$ ) and $1.92 \pm 1.00$ ha (median $=1.01$, range $0.48-5.89$ ha), respectively; and $90 \%$ and $95 \%$ dBBMM were $0.97 \pm 0.04$ ha (median $=0.97$, range $0.86-1.07 \mathrm{ha}$ ) and $2.34 \pm 0.01$ ha 
Table 3. Home range overlap of C. macrops (CRMA) and V. vogeli (VIVO) with minimum convex polygon (MCP, $100 \%$ ) analysis of home range overlap (ha and \%) and fixed kernel (FK, 50 and $99 \%$ ) overlap with Bhattacharyya's affinity (BA), volume of intersection index (VI), and utilisation distribution overlap index (UDOI). There was no overlap detected with any other combinations of individuals.

\begin{tabular}{|cc|cc|ccc|ccc|}
\hline \multicolumn{2}{|c|}{$\begin{array}{c}\text { Viper IDs } \\
\text { Overlapping pairs }\end{array}$} & \multicolumn{2}{c|}{ MCP } & \multicolumn{3}{c|}{$\mathbf{5 0} \%$ FK } & \multicolumn{2}{c|}{$\mathbf{9 9} \%$ FK } \\
\hline CRMA174 & VIVO003 & 0.111 & 8.3 & 0.00479 & 0.0014 & 0.00002 & 0.16501 & 0.05628 & 0.07662 \\
CRMA186 & VIVO002 & 0 & 0 & 0 & 0 & 0 & 0.00762 & 0.00356 & $8.00 \mathrm{E}-05$ \\
\hline
\end{tabular}

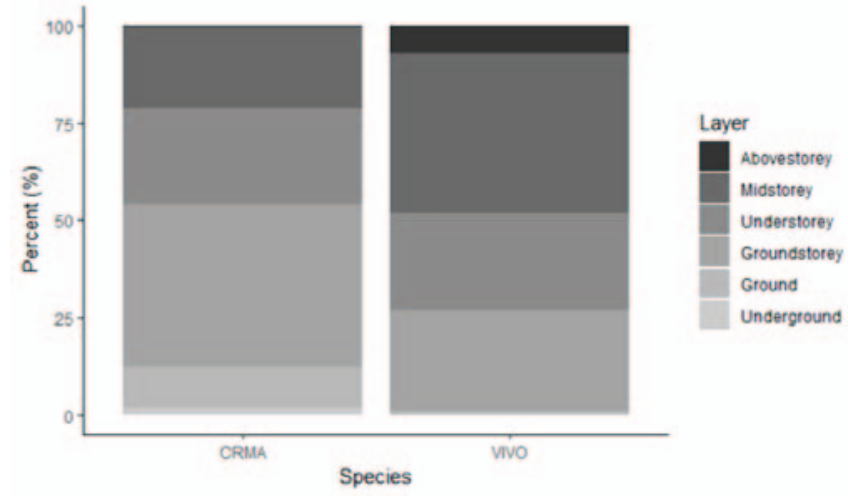

Figure 3. Summary of the percentage of fixes of $C$. macrops (CRMA) and $V$. vogeli (VIVO) that were below ground level (underground), on the ground (ground), <1 $\mathrm{m}$ above ground level (groundstorey), 1-3 $m$ above ground level (understorey), 3-10 $m$ above ground level (midstorey), and $>10 \mathrm{~m}$ above ground level (abovestorey)

(median $=2.34$, range 2.33-2.34 ha), respectively (Table 2, Fig. 2). Viridovipera vogeli had greater displacements (but did not move more frequently) and had larger home ranges than C. macrops (Table 2). Home range overlap between study vipers was minimal, and intraspecific overlap was not observed (Fig. 2 \& Table 3).

During the 78 day study period, we observed that the two $V$. vogeli were in "arboreal" locations (> $3 \mathrm{~m}$ above ground level, mean $53.0 \pm 14.4 \%$, median $=53.05$, of observations) more often than $C$. macrops (mean $23.4 \pm 13.2 \%$, median $=15.7$, of observations, Table 1, Fig. 3). This difference was statistically significant $\left(\chi^{2}=25.0565, \mathrm{df}=1, \mathrm{p}<0.001\right)$. The $C$. macrops were most frequently observed at the groundstorey level ( $<1 \mathrm{~m}$ above ground, 101 observations, $41.6 \%$ of total observations for this species), while the $V$. vogeli were most often observed at the abovestorey level (3- $10 \mathrm{~m}$ above ground, 46 observations, $41.1 \%$ of total observations for this species).

\section{DISCUSSION}

Both green pit viper species in our study exhibited limited movement and small home ranges. This is consistent with their ambush foraging strategy (Macartney et al., 1988). However, $V$. vogeli moved further and exhibited larger home ranges than $C$. macrops. This was to be expected as larger individuals and species typically require larger home ranges for foraging (McNab, 1963).

Traditional home range estimators (MCP, kernels, etc.) are imperfect estimators for organisms with limited movement and small home range size such as green pit vipers. The MCP method includes large areas of unused space and does not take movement into account (Nilsen et al., 2008), while kernels generally overestimate overall home range size (Row \& Blouin- Demers, 2006). To date, the dBBMM method has only been used for one other snake species, the king cobra (Ophiophagus hannah), which displays significantly larger home ranges. However, this study suggests that dBBMMs are better at optimising the trade- off between Type I and Type II errors (under and over smoothing, respectively), displaying ecological patterns of habitat selection, addressing spatial autocorrelation of telemetry points, and providing insights into seasonal and habitat variation compared to MCP and kernel methodologies (Silva et al., 2018). All of our spatial methods, and coincidently those currently used by snake ecologists, fail to incorporate vertical movement and space use which limits ecological inferences for arboreal species such as green pit vipers. Innovative home range and overlap techniques have been developed to incorporate vertical movement and stratification (i.e. Cooper et al., 2014); however, these methods require much more movement and continuous height measurements than traditional methods.

Snakes are not known to display territorial behaviour, and individuals of the same species and population usually exhibit widely overlapping home ranges (see review by Gregory et al., 1987; Weatherhead \& Hoysak, 1989; Secor, 1994). It appears that both specimens of $V$. vogeli in our study had home ranges that overlapped those of $C$. macrops. No intraspecies overlap was observed, and one $C$. macrops (CRMA178) home range did not overlap any other study viper home range. Small home range size, particularly by $C$. macrops, may best explain the limited home range overlap observed but overlap with non- tracked individuals cannot be ruled out.

The two species in our study clearly used separate strata levels within the dry evergreen forest during the cold inactive season. We cautiously suggest that vertical stratification of these two sympatric vipers may be one factor facilitating the co-existence of otherwise morphologically similar species. However, there has been no previous comprehensive study of behaviour, prey selection, habitat selection, or thermal preference of either $C$. macrops or $V$. vogeli, which are factors that could influence this partitioning of space. It is clear that vertical niche partitioning of green pit vipers requires further investigation with larger sample sizes across all seasons. Intraspecific niche partitioning has been suggested previously for C. macrops (Strine et al., 2015), and similar studies with $V$. vogeli may further support both intraspecific niche partitioning as well as the vertical niche partitioning 
that our results suggest. Further study may yield significant insight into green pit vipers (particularly $V$. vogeli), tropical species interactions, and snakes in general.

\section{ACKNOWLEDGEMENTS}

We thank Suranaree University of Technology (SUT) for supporting this project. All methods were carried out under the guidelines and approval of the SUT animal use and ethics committee. The Thailand Institute of Scientific and Technological Research (TISTR) and Sakaerat Environmental Research Station (SERS) provided funding, site permission, and logistical and technical support throughout the project.

\section{REFERENCES}

Barnes, C.H., Strine, C.T., Suwanwaree, P., \& Hill III, Jacques. (2017). Movement and home range of green pit vipers (Trimeresurus spp.) in a rural landscape in northeast Thailand. Herpetological Bulletin 142: 19-28.

Bhattacharyya, A. (1943). On a measure of divergence between two statistical populations defined by their probability distributions. Bulletin of the Calcutta Mathematical Society 35: 99-109.

Calabrese, J.M., Fleming, C.H., \& Gurarie, E. (2016). ctmm: an $\mathrm{R}$ package for analyzing animal relocation data as a continuous-time stochastic process. Methods in Ecology and Evolution 7: 1124-1132.

Calenge, C. (2006). The package adehabitat for the $R$ software: tool for the analysis of space and habitat use by animals. Ecological Modelling 197: 516-519.

Chesson, P. (2000). General theory of competitive coexistence in spatially-varying environments. Theoretical Population Biology 58: 211-237.

Cooper, N.W., T.W. Sherry, \& Marra, P.P. (2014). Modeling three-dimensional space use and overlap in birds. Auk: Ornithological Advances 131: 681-693.

David, P., Vidal, N., \& Pauwels, O.S.G. (2001). A morphological study of Stejneger's pitviper Trimeresurus stejnegeri (Serpentes, Viperidae, Crotalinae), with a description of a new species from Thailand. Russian Journal of Herpetology 8: 205-222.

ESRI (2012). ArcGIS Desktop and Spatial Analyst Extension: Release 10.1. Environmental Systems Research Institute, Redlands, CA.

Fieberg, J., \& Kochanny, C.O. (2005). Quantifying homerange overlap: the importance of the utilization distribution. Journal of Wildlife Management 69: 13461359.

Gause, G. F. (1934). The struggle for existence. Williams and Wilkens, Baltimore.

Gregory, P.T., Macartney, J.M, \& Larsen, K.W. (1987). Spatial patterns and movements. In Snakes: Ecology and Evolutionary Biology, eds. Seigel, R.A., Collins, J.T., \& Novak, S.S. Macmillan, New York, pp. 366395.

Hardy, D.L., \& Greene, H.W. (2000). Inhalation of anesthesia of rattlesnakes in the field for processing and transmitter implantation. Sonoran Herpetology 13: 109-113.
Karelus, D.L., McCown, J.W., Scheick, B.K., \& Oli, M.K. (2018). Microhabitat features influencing habitat use by Florida Black Bears. Global Ecology and Conservation 13(2017): e00367.

Kernohan, B.J., Gitzen, R.A., \& Millspaugh, J.J. (2001). Analysis of animal space use and movements. In: Millspaugh, J.J., \& Marzluff, J.M. (eds). Radiotracking and Animal Populations San Diego: Academic Press. pp. 126-166.

Kranstauber, B., Kays, R., Lapoint, S.D., Wikelski, M., \& Safi, K. (2012). A Dynamic Brownian Bridge Movement Model to Estimate Utilization Distributions for Heterogeneous Animal Movement. Journal of Animal Ecology 81: 738746.

Kramer, E. (1977). Zur schlangenfauna Nepals. Revue Suisse Zoologie 84: 721-761.

Macartney, J.M., Gregory, P.T., \& Larsen, K.W. (1988). A tabular survey of data on movements and home ranges of snakes. Journal of Herpetology 22: 61-73.

Malhotra, A., Thorpe, R.S., \& Stuart, B.L. (2004). A morphometric analysis of Trimeresurus vogeli (David, Vidal and Pauwels, 2001), with new data on diagnostic characteristics, distribution and natural history. Herpetological Journal 14: 65-78.

McNab, B.K. (1963). Bioenergetics and the determination of home range size. American Naturalist 97: 133-140.

Nielson, R.M., Sawyer, H., \& McDonald, T.L. (2013). BBMM: Brownian bridge movement model for estimating the movement path of an animal using discrete location data. $\mathrm{R}$ package version 3.0. http://CRAN.Rproject.org/ package=BBMM (accessed July 2019).

Nilsen, E.B., Pedersen, S., \& Linnell, J.D. (2008). Can minimum convex polygon home ranges be used to draw biologically meaningful conclusions? Ecological Research 23: 635-639.

Ongsomwang, S., \& Sutthivanich, I. (2014). Integration of remotely sensed data and forest landscape pattern analysis in Sakaerat Biosphere Reserve. Suranaree Journal of Science and Technology 21: 233-248.

Orlov, N. L., Ananjeva, N., \& Khalikov, R. (2002). Natural history of pitvipers in eastern and southeastern Asia. In: Biology of the Vipers, pp. 345-359. Schuett, G.W., Hoggren, M., Douglas, M.E., \& Greene, H.W. (editors). Eagle Mountain, USA, Eagle Mountain Publishing.

Pacala, S., \& Roughgarden, J. (1982). Resource partitioning and interspecific competition in two two- species insular Anolis lizard communities. Science 217: 444-446.

QGIS (version 2.12.3). Quantum GIS Development Team (2016). Quantum Geographic Information System.

R Development Core Team. (2010). R: A Language and Environment for Statistical Computing. R Foundation for Statistical Computing, Vienna, Austria.

Reinert, H.K., \& Cundall, D. (1982). An improved surgical implantation method for radio-tracking snakes. Copeia 1982: 702-705.

Roughgarden, J. (1976). Resource partitioning among competing species - a coevolutionary approach. Theoretical Population Biology 9: 388-424.

Row, J.R., \& Blouin-Demers, G. (2006). Kernels are not accurate estimators of home- range size for herpetofauna. Copeia 2006: 797-802. 
Secor, S.M. (1994). Ecological significance of movements and activity range for the sidewinder, Crotalus cerastes. Copeia 1994: 631-45.

Seidel, K.S. (1992). Statistical properties and applications of a new measure of joint space use for wildlife. Thesis, University of Washington, Seattle, USA.

Shine, R., \& Wall, M. (2007). Why is intraspecific niche partitioning more common in snakes than in lizards? In Lizard Ecology. The Evolutionary Consequences of Foraging Mode (eds S. M. Reilly, L. D. McBrayer \& D. B. Miles), Cambridge University Press, Cambridge, pp 173208.

Silva, I., Crane, M., Suwanwaree, P., Strine, C., \& Goode, M. (2018). Using dynamic Brownian Bridge Movement Models to identify home range size and movement patterns in king cobras. PloS one 13: p.e0203449.

Strine, C., Silva, I., Nadolski, B., Crane, M., Barnes, C., Artchawakom, T., Hill, J., \& Suwanwaree, P. (2015). Sexual dimorphism of tropical Green Pit Viper Trimeresurus (Cryptelytrops) macrops in Northeast Thailand. AmphibiaReptilia 36: 1-12.

Stuart, B., Chan-Ard, T., \& Thy, N. (2012). Cryptelytrops macrops. The IUCN red list of threatened species. Version 2015.1. www.iucnredlist.org (accessed June 2015).

Tiebout, H.M., \& Cary, J.R. (1987). Dynamic spatial ecology of the water snake, Nerodia sipedon. Copeia 1987: 1-18.

Toft, C.A. (1985). Resource partitioning in amphibians and reptiles. Copeia 1985: 1-21.
Trisurat, Y., Alkemade, R., \& Aretsk, E. (2009). Projecting forest tree distributions and adaptation to climate change in northern Thailand. Journal of Ecology and the Natural Environment 1: 55-63.

Vogel, G., David, P., \& Sidik, I. (2014). On Trimeresurus sumatranus (Raffles, 1822), with the designation of a neotype and the description of a new species of pit viper from Sumatra (Squamata: Viperidae: Crotalinae). Amphibian and Reptile Conservation 8: 1-29.

Walter, W.D., Fischer, J.W., Baruch-Mordo, S., \& VerCauteren, K.C. (2011). What is the proper method to delineate home range of an animal using today's advanced GPS telemetry systems: the initial step. Modern telemetry. IntechOpen (accessed July 2019).

Weatherhead, P.J., \& Hoysak, D.J. (1989). Spatial and activity patterns of black rat snakes (Elaphe obsoleta) from radiotelemetry and recapture data. Canadian Journal of Zoology 67: 463-468.

Wilkinson, S.L. (2014). Guide to venomous reptiles in veterinary practice. Journal of Exotic Pet Medicine 23: 337-346.

Wisheu I. R. (1998). How organisms partition habitats: Different types of community organization can produce identical patterns. Oikos 83: 246-58.

Accepted: 22 August 2019 